\title{
An overview of the management of renal malignancies in von Hippel-Lindau syndrome \\ Umesh Jayarajah ${ }^{1}$, Oshan Basnayake', Vimalakanthan Thanusan², Balasingam Balagobi ${ }^{3}$, Madura Ambegoda ${ }^{1}$, Anuruddha M Abeygunasekera ${ }^{1}$ \\ ${ }^{1}$ Department of Urology, Colombo South Teaching Hospital, Kalubowila, Sri Lanka \\ ${ }^{2}$ Department of Urology, Teaching Hospital, Jaffna, Sri Lanka \\ ${ }^{3}$ Department of Surgery, University of Jaffna, Jaffna, Sri Lanka
}

Keywords: Von Hippel-Lindau syndrome; VHL; renal cell carcinoma

\begin{abstract}
Von Hippel-Lindau [VHL] syndrome is a hereditary multisystem cancer syndrome characterized by a wide range of benign and malignant tumours. Renal neoplasms are the commonest solid organ malignancies associated with VHL seen in $25-45 \%$ of patients. Management of renal tumours is determined by multiple tumour related and patient-related factors and decision making is often difficult due to its multifocal nature and bilateral involvement. Its tendency for frequent recurrences further complicates the clinical picture. We review the existing literature on the management of renal malignancies in VHL syndrome focussing on observational strategies, minimally invasive approaches, nephron-sparing surgery and radical surgery. Furthermore, we provide the Sri Lanka perspective in the management of renal malignancies in VHL syndrome. Surgeons that manage such patients should be cognizant of extra-renal manifestations of VHL and the importance of a multidisciplinary team and referral pathways. Proper follow-up and selecting patients for suitable as well as minimal interventions such as minimally invasive techniques and nephron-sparing approaches is crucial in the management to provide acceptable cancer control while preserving renal functions. In Sri Lanka, establishing proper referral pathways to dedicated centres with a multidisciplinary team equipped with facilities to deal with renal as well as extra-renal manifestations would improve expertise, quality of care and reduce patient discomfort and default rate.
\end{abstract}

\section{Introduction}

Von Hippel-Lindau [VHL] syndrome is a hereditary multisystem cancer syndrome with an incidence of 1:36000 live births [1]. Around 4\% of renal cancers are estimated to be associated with hereditary cancer syndromes [2]. Of which, VHL was the first hereditary cancer syndrome to be described in association with renal cancers.

Correspondence: Umesh Jayarajah

E-mail: umeshe.jaya@gmail.com

(i) https://orcid.org/0000-0002-0398-5197

Received: 08-09-2021 Accepted: 27-11-2021

DOI: http://doi.org/10.4038/sljs.v39i3.8889
Renal neoplasms are the commonest solid organ malignancies associated with VHL seen in $25-45 \%$ of patients [2]. It develops due to a germline mutation of the VHL tumour suppressor gene in the short arm of chromosome 3 [3]. VHL has an autosomal dominant inheritance through familial transmission, however, $20 \%$ of the patients may develop due to sporadic mutation [4]. Its wide spectrum of clinical manifestations demands clinical attention through multiple disciplines. VHL syndrome is characterized by a wide range of benign and malignant tumours. These include central nervous system [CNS] tumours commonly cerebellar haemangioblastomas, retinal angiomas, renal tumours, pheochromocytomas, endolymphatic sac tumours, pancreatic cystic lesions and neuroendocrine tumours and cystadenomas in the epididymis and broad ligament.

Among these tumours, management of renal tumours is determined by multiple tumour related and patient-related factors and decision making is often difficult due to its multifocal nature and bilateral involvement. Its tendency for frequent recurrences further complicates the clinical picture. We review the existing literature on the management of renal malignancies in VHL syndrome. Furthermore, we provide the Sri Lankan perspective in the management of renal malignancies in VHL syndrome.

\section{Genetics and pathogenesis}

Transcription of the VHL gene results in a protein complex responsible for the degradation of hypoxia-inducible factor [HIF]. HIF is otherwise responsible for the enhanced expression of angiogenic and growth factors such as VEGF [angiogenic], PDGF $\beta$ [growth] and TGF $\alpha$ [mitogenic] which promote cellular proliferation. So failed degradation of HIF would result in overexpression of the above proteins which ultimately leads to uncontrolled cellular proliferation resulting in carcinogenesis. HIF independent mechanisms also exist which involve loss of extracellular matrix framework via fibronectin which further contributes to carcinogenesis [Figure 1] [5, 6].

The Sri Lanka Journal of Surgery 2021; 39(3): 65-70 


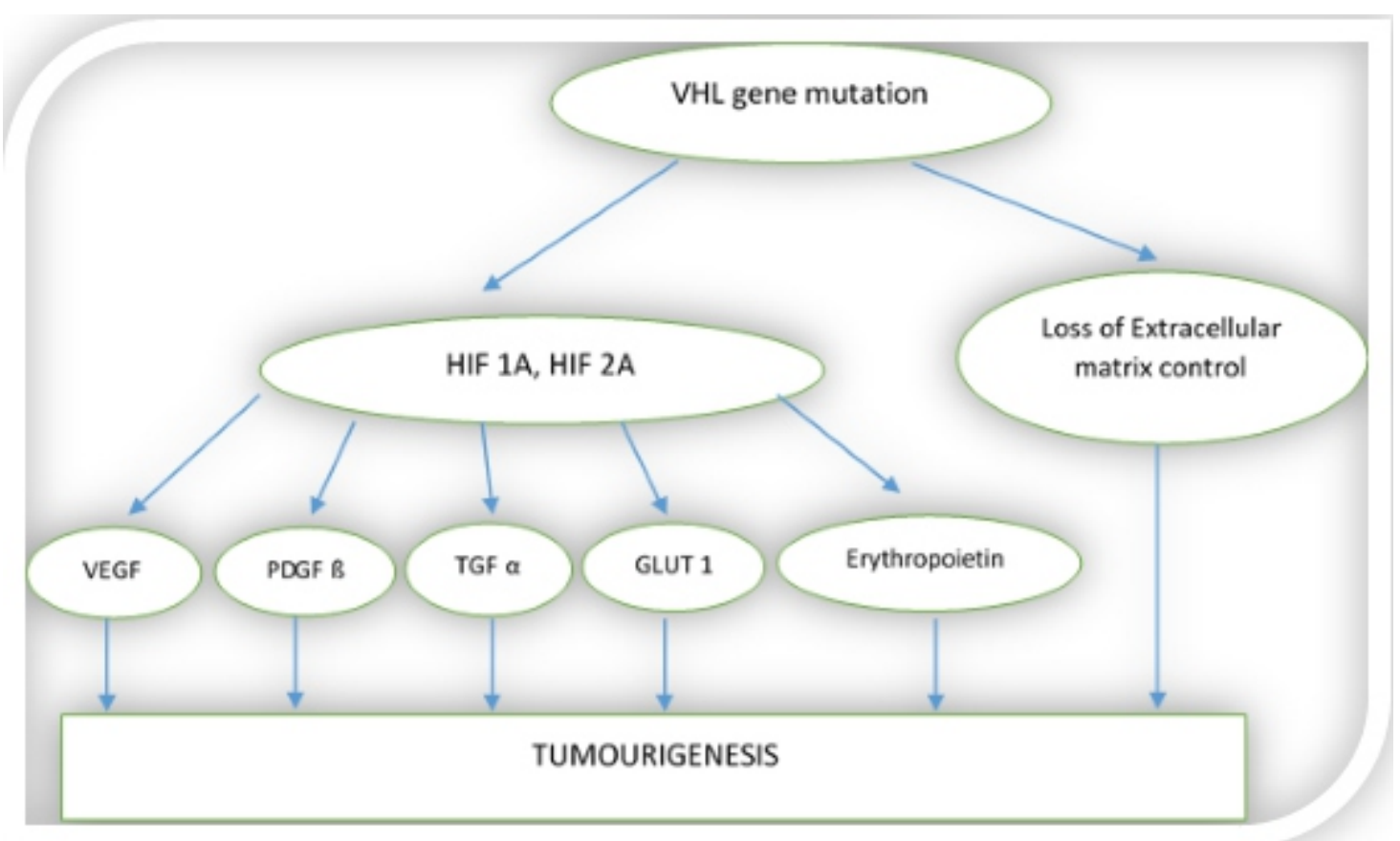

Figure 1. The genetic basis of carcinogenesis/ tumorigenesis in VHL syndrome

This disease is an excellent example of Knudson's two-hit hypothesis [3]. As the mutated gene is already present in one allele of all the cells, the development of the disease requires a second hit on the remaining allele. Either the somatic mutation, deletion, loss of functional variants or methylation of this gene manifests the disease in vulnerable organs. The type of mutation determines the phenotype of the disease [7]. For example, a missense mutation is mostly associated with pheochromocytoma.

VHL is classified into two types according to the presence of phaeochromocytoma [7]. The presence of missense mutation is more likely to cause pheochromocytoma as in type 2 [with either high risk or low risk for concurrent renal cell carcinoma] and mostly, the deletion and loss of functional variants would cause type 1 disease with a very low risk of phaeochromocytoma [Table 1].

Table 1. Classification of VHL syndrome into type 1 and 2

\begin{tabular}{|l|l|}
\hline Type & Organ manifestations \\
\hline Type 1 & Very low risk of pheochromocytoma \\
\hline & $\begin{array}{l}\text { CNS Haemangioblastomas, pancreatic lesions, } \\
\text { Renal cell carcinoma [RCC] }\end{array}$ \\
\hline Type 2 & $\begin{array}{l}\text { A - Pheochromocytoma, CNS tumours, } \\
\text { Retinal tumours }\end{array}$ \\
\hline & B - Above [A] + RCC, Pancreatic lesions \\
\hline & C - Pheochromocytomas \\
\hline
\end{tabular}

\section{Screening and diagnosis of VHL syndrome and renal} tumours

During the process of genetic testing, the altered gene will be detected in peripheral leucocytes almost always in familial inherited cases. In cases with de novo mutation, the mutated gene might not be present in all cell types [mosaicism] and therefore may or may not be seen in peripheral leucocytes. The possibility of transmitting the gene to their offspring is also affected by the presence of a mutation in germ tissues [3, 8].

VHL gene analyses are available with $100 \%$ accuracy in experienced laboratories but they are expensive [2]. Clinical criteria for VHL syndrome are very useful in the diagnosis in resource-limited settings [9]. The clinical diagnosis criteria vary with the presence of family history. In patients with a positive family history of VHL, one or more of the following lesions including retinal hemangioblastoma, cerebellar or spinal cord haemangioblastoma, phaeochromocytoma, renal clear cell carcinoma or multiple renal or pancreatic cysts would suffice. In the absence of family history, two or more of the following groups of lesions should be present. These include i] $\geq 2$ retinal, spinal cord or brain hemangioblastomas, or a single hemangioblastoma in addition to visceral organ lesions [multiple renal or pancreatic cysts]; ii] renal clear cell carcinoma; iii] adrenal or extra-adrenal pheochromocytoma and iv] rare lesions including internal lymphoma, papillary cystadenoma of the epididymis and broad ligament, and neuroendocrine tumours of the pancreas [9]. VHL genetic test is warranted in those with atypical manifestations without a family history. Genetic testing should be offered following 


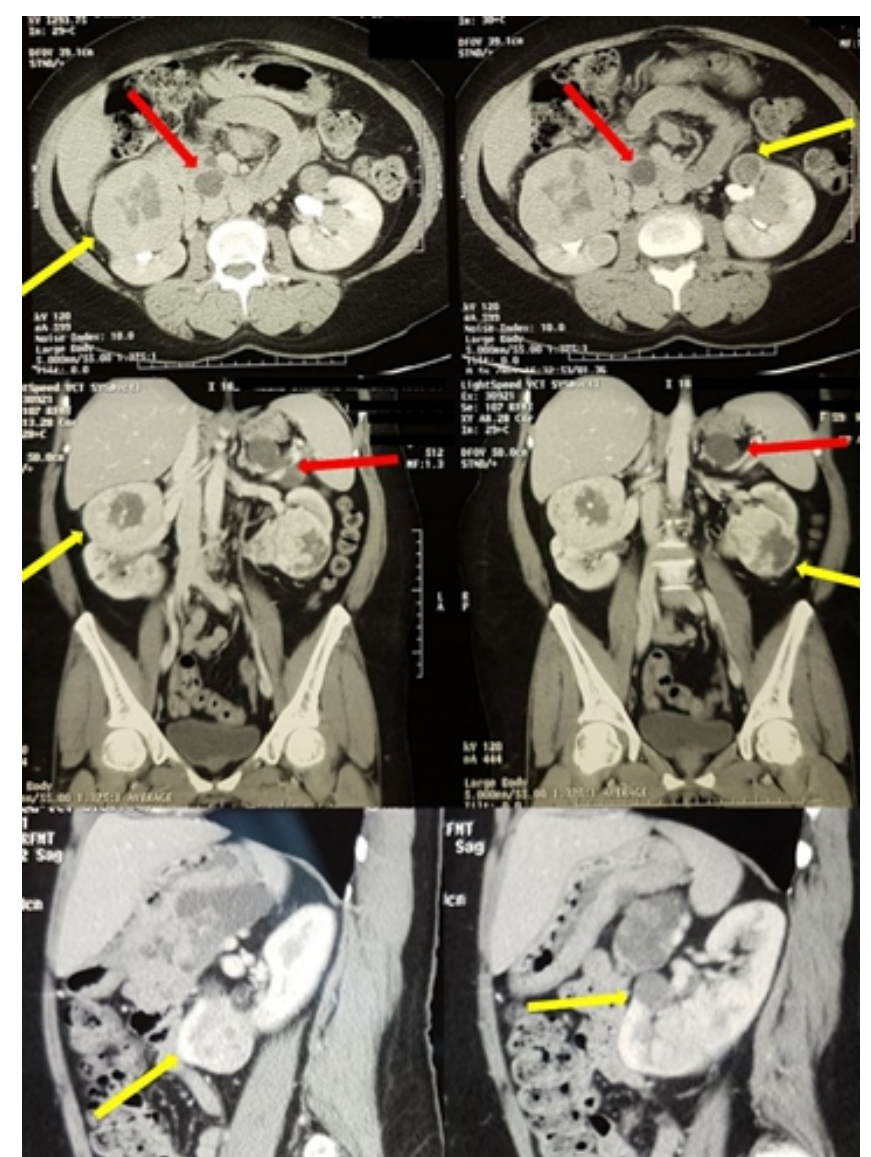

Figure 2. CT scan images of renal tumours in VHL syndrome showing bilateral solid and cystic lesions indicated by yellow arrows. Pancreatic cystic lesions are indicated by red arrows

detailed genetic counselling.

Renal manifestations are typically characterised by multiple renal cysts and renal tumours often as clear cell renal cell carcinomas [RCC]. Development of renal tumours are rare before the age of 20 years and the mean age is 44 years [10]. Although RCC may present with haematuria, the presence of this symptom indicates a late stage of the disease [11]. Before the utility of computed tomography CT scans, $13-42 \%$ of the patients died due to metastatic complications of the disease [11]. At present, mostly, these lesions are detected as part of the surveillance process because the initial presentation is usually of non-renal pathology such as CNS tumours.

In patients diagnosed with VHL syndrome, contrastenhanced [CT] of the abdomen and pelvis is usually performed to detect visceral lesions starting at the age of 18 and further frequency of follow up imaging is determined by the disease manifestations [Figure 2] [12]. Renal tumours are seen as simple or complex cystic lesions or solid renal masses [12]. Ultrasonography [USS] or abdominal magnetic resonance imaging [MRI] are useful to further characterise indeterminate lesions. Additional investigations include serum metanephrines for pheochromocytoma and MRI of the brain and ophthalmological assessment for CNS and eye manifestations [2].

\section{Management of renal malignancies in VHL syndrome}

Management strategy should involve a multidisciplinary approach due to the complexity of the disease and concurrent bilateral involvement [Figure 3]. A high chance of recurrence renders the patients more prone to repeated surgical intervention and subsequent loss of renal function. The management approach for malignant renal tumours is more towards nephron-sparing treatment options keeping in mind to optimally preserve renal parenchyma. Strategies to preserve the functional status of remnant renal tissue should also be considered with optimization of patient comorbidities such as diabetes, hypertension .etc.

\section{Nephron sparing surgery [NSS]}

A major difficulty in decision making is when the patient is having bilateral multifocal tumours, especially if one or more of them are exceedingly large. Nephron sparing approaches should be considered first without compromising the oncological outcome to delay the renal replacement therapy due to surgical intervention. Improvements in imaging modalities such as USS, CT and MRI have contributed to the effective surveillance programme and smaller tumours $[<$ $3 \mathrm{~cm}$ ] with low malignant potential can be safely monitored [11]. The consensus cut off for surgical management in VHL is taken as more than $3 \mathrm{~cm}$ [11]. Apart from the size of the tumour, age of diagnosis, synchronous tumours and type of mutation was associated with the rate of growth of VHL tumours are considered in the setting of non-surgical management [13]. A multicentre study of RCC in VHL patients showed higher cancer-specific 5-year survival in

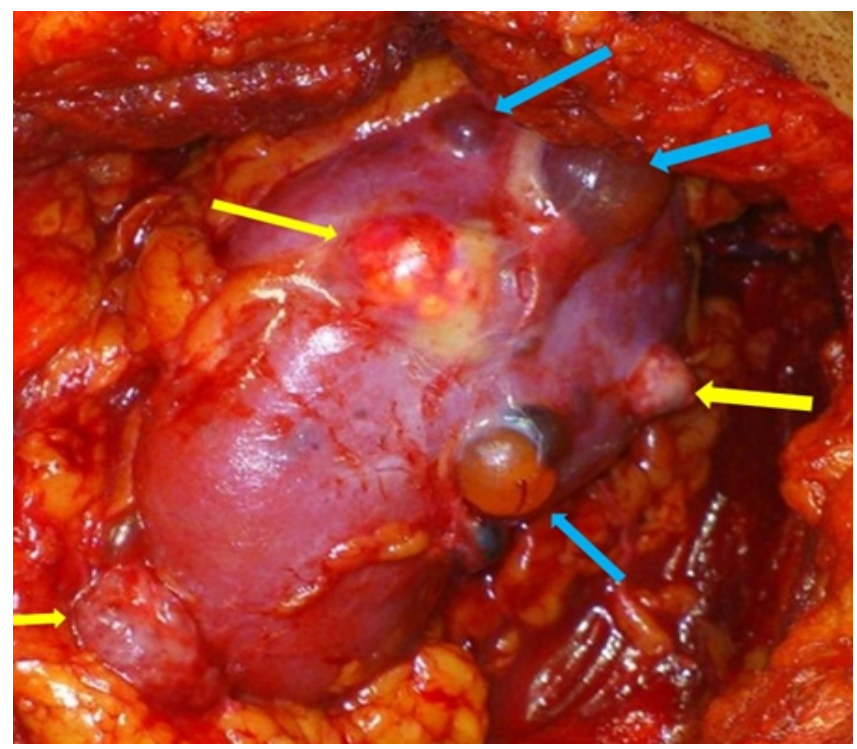

Figure 3. Image showing a kidney with multiple tumours [yellow arrows] and cysts [blue arrows] 
NSS compared to radical nephrectomy [100\% vs. 95\%] [14].

Studies have shown the value of intraoperative USS in NSS for hereditary renal cancer syndromes where $25 \%$ of occult lesions were detected. However, further studies are needed before recommendations for routine practice [15]. Apart from the general advantages of laparoscopy, the place for laparoscopic NSS may be beneficial to prevent access-related complications in future operations. Otherwise, the advantage of laparoscopy in NSS is uncertain but a relatively shorter duration of acute kidney injury [AKI] [Odds ratio [OR]: 3.87] was observed in one study [16]. The exact role of laparoscopic partial nephrectomy, and the ideal patients for this procedure, has yet to be determined.

In cases where there are bilateral tumours requiring radical nephrectomy on one side and NSS on the other, performing both surgeries simultaneously may lead to a higher chance of AKI, especially in patients with already compromised renal function. In such cases, it may be advisable to avoid simultaneous bilateral surgeries.

Performing one side, specifically, the NSS first may allow adequate time for the operated kidney to recover from surgery. This might help in reducing the morbidity due to AKI during the subsequent operation following a waiting time of 4-6 weeks [17].

\section{Radical Nephrectomy}

Radical nephrectomy should be preserved for the patients in whom an NSS does not allow a significant functioning future renal remnant. Roupret et al suggested that VHL associated RCCs tend to be bilateral and multifocal and have a high chance of local recurrence following NSS [18]. The chance of recurrence and metastatic potential is more if the tumour size is more than $7 \mathrm{~cm}$. These types of patients often require a more invasive approach.

Very rarely, bilateral tumours which are not amenable for nephron-sparing approaches or associated with the end-stage renal disease require bilateral radical nephrectomy with renal replacement therapy [RRT]. There are concerns regarding tumour recurrence with subsequent immunosuppressive therapy following renal transplant and the optimal latency time between nephrectomy and transplantation [19]. In a case-control study, Goldfarb et al found no difference in renal function, graft survival and patient survival between patients with VHL who underwent transplant after a mean duration of dialysis of 26 months and the control group [transplant patients without VHL] [20]. Furthermore, there was no association between the pre-transplant dialysis period and subsequent development of metastatic disease [20]. However, more evidence is needed before recommendations. A special emphasis is required in live related donor transplantation because of the risk of the donor having VHL mutation which might cause the development of RCC in the remaining kidney.

\section{Minimally invasive techniques}

Minimally invasive focal therapies such as radiofrequency ablation, cryoablation and microwave therapy via either percutaneous or laparoscopic approaches show promising oncological outcomes with sparing of renal parenchyma in treating smaller tumours that are recurrent and multifocal [21]. However, these patients need more frequent monitoring and follow up. Furthermore, due to the possibility of multiple lesions, preoperative high-quality imaging and discussion with a radiologist are important [2]. Experience with ablative procedures in VHL patients is increasing globally and even in the local setting. A case series from Sri Lanka has shown successful implementation of ablative procedures [17].

A 10-year retrospective study on percutaneous cryoablation performed among 308 patients with renal tumours showed local recurrence and metastasis rates of $10.1 \%$ and $6.2 \%$ respectively [22]. However, in this study, only 6 patients had VHL syndrome [22]. In another series of 14 VHL patients [12 had a single kidney], salvage probe ablative therapy was performed in 33 tumours [average diameter $2.6 \pm 1 \mathrm{~cm}$ ] using percutaneous cryoablation $[\mathrm{n}=13]$, radiofrequency ablation $[\mathrm{n}=14]$, and laparoscopic cryoablation $[\mathrm{n}=3$ without significant complications or reduction in renal functions [23]. During a mean follow-up of 37.6 months [range 12-82], CT or MRI showed suspicion of recurrence in 4 patients of which, 3 underwent re-ablation. The cancer-specific and overall survivals were $100 \%$ and $92 \%$ respectively [23].

There is more data with RFA than with cryoablation for the treatment of renal tumours associated with VHL syndrome [2, 24]. The ideal size of a tumour should be between $1 \mathrm{~cm}$ and 3 $\mathrm{cm}$ for ablation and a $5 \mathrm{~mm}$ margin is needed for complete ablation by RFA [24]. A cystic or solid lesion measuring $1 \mathrm{~cm}$ should be monitored until it increases more than $1 \mathrm{~cm}$ before ablation. Tumours less than $1 \mathrm{~cm}$ are not ablated due to difficult characterisation, difficult targeting for ablation and very low risk of metastasis even if they contain RCC [24]. The major complication rates for ablative procedures are $0-8 \%$ in VHL disease which is lower than surgical resection $6-14 \%$ [24]. Major complications following ablation include intestinal perforation, ureteral strictures, bleeding requiring intervention and residual or recurrent tumours [24].

In VHL disease, regular follow up of renal lesions is recommended due to high recurrence rates. Generally, crosssectional imaging should be conducted at least yearly to detect recurrences in these high-risk patients [24]. 


\section{Observational strategies}

Simple renal cysts are usually followed up without any invasive interventions as they are usually asymptomatic and the risk of containing RCC is very low. Complex renal cysts should be monitored with close observation and serial imaging with a specific focus on their malignant potential. Solid components in otherwise benign-looking renal cysts contain foci of RCC.

Tumours smaller than $3 \mathrm{~cm}$ can be followed up with close surveillance due to their seemingly low metastatic potential. Walther et al suggested that nephron-sparing surgery in small tumours with the threshold of tumour diameter as $3 \mathrm{~cm}$ showed favourable outcomes about metastasis and renal function [25]. However, with the newer ablation techniques tumours larger than $1 \mathrm{~cm}$ are subjected to ablation without waiting for the tumour to exceed $3 \mathrm{~cm}$, to avoid invasive surgery.

\section{Sri Lankan perspective}

According to 2018 GLOBOCAN estimates, renal cancers are the 15th commonest cancer with an age-standardised rate of 0.8 per 100,000 population [26]. The data on the proportion of VHL among RCC patients is restricted to tertiary care centres $[27,28]$. A cohort from a tertiary care centre showed that out of 285 renal cell carcinomas only 6 patients [2.1\%] had VHL syndrome [17, 27]. In Sri Lanka, renal cancer patients are treated by urologists, once surgeons and general surgeons throughout the country. The majority of cancer care is delivered through government hospitals although the private sector also plays a role in the urban setting [29]. However, renal cancers associated with VHL syndrome should be managed by experienced centres with a multidisciplinary team with necessary minimally invasive treatment facilities and facilities for managing other manifestations of VHL.

The data on the clinical characteristics and outcomes of renal tumours with VHL syndrome is very limited in Sri Lanka. Only 1 case series described 6 patients, [mean age $=35.1$ years [range: 24-54], males $=5$ ] with VHL syndrome with multiple bilateral renal malignancies with a median follow-up of 36 months [range: 12-72]. Different combinations of radical nephrectomy $[n=2]$, partial nephrectomy $[n=7]$ and focal therapy $[n=6]$ were used appropriately. Only two patients developed new lesions which were successfully managed with focal therapy [17].

A proper referral and prospective registry is needed for these patients for better management, follow up and further research. Due to the epidemic of chronic kidney disease in Sri Lanka, demands for RRT is high and patients are concerned about RRT due to the financial implications. Patients often face psycho-social disturbances due to the stigma related to hereditary cancers and the risk of needing future RRT [17]. Thus sometimes, patients are reluctant to divulge the positive family history. Therefore, clinicians should be aware of this and be empathetic towards these psychosocial problems. Counselling regarding the availability of treatment in the form of surgery and minimally invasive procedures would reduce the anxiety of patients [17].

\section{Conclusion}

VHL is a hereditary cancer syndrome associated with recurrent, bilateral and multifocal tumours.

Surgeons that manage such patients should be cognizant of extrarenal manifestations of VHL and the importance of a multidisciplinary team and referral pathways. Proper followup and selecting patients for suitable as well as minimal interventions such as minimally invasive techniques and NSS-based approaches is crucial in the management to provide acceptable cancer control while preserving renal functions. In Sri Lanka, establishing proper referral pathways to dedicated centres with a multidisciplinary team equipped with facilities to deal with renal as well as extra-renal manifestations would improve expertise, quality of care and reduce patient discomfort and default rate. Additional Information and Disclosures

All authors disclose no conflict of interest. The study was conducted in accordance with the ethical standards of the relevant institutional or national ethics committee and the Helsinki Declaration of 1975, as revised in 2000 .

\section{References}

1. Maher ER, Iselius L, Yates JR, Littler M, Benjamin C, Harris R, et al. Von Hippel-Lindau disease: a genetic study. Journal of Medical Genetics. 1991;28(7):443-7. doi: 10.1136/jmg.28.7.443 https://doi.org/10.1136/jmg.28.7.443

2. Grubb RL, 3rd, Choyke PL, Pinto PA, Linehan WM, Walther MM. Management of von Hippel-Lindau-associated kidney cancer. Nature Clinical Practice Urology. 2005;2(5):248-55.

https://doi.org/10.1038/ncpuro0179

3. Lonser RR, Glenn GM, Walther M, Chew EY, Libutti SK, Linehan WM, et al. von Hippel-Lindau disease. Lancet. 2003;361(9374):2059-67.

https://doi.org/10.1038/ncpuro0179

4. Varshney N, Kebede AA, Owusu-Dapaah H, Lather J, Kaushik M, Bhullar JS. A Review of Von Hippel-Lindau Syndrome. Journal of Kidney Cancer and VHL. 2017;4(3):20-9. https://doi.org/10.15586/jkcvhl.2017.88

5. Kaelin WG, Jr. Molecular basis of the VHL hereditary cancer syndrome. Nature Reviews Cancer. 2002;2(9):673-82.

https://doi.org/10.1038/nrc885

6. Barry RE, Krek W. The von Hippel-Lindau tumour suppressor: a multi-faceted inhibitor of tumourigenesis. Trends in Molecular Medicine. 2004;10(9):466-72.

https://doi.org/10.1016/j.molmed.2004.07.008 
7. Ong KR, Woodward ER, Killick P, Lim C, Macdonald F, Maher ER. Genotype-phenotype correlations in von Hippel-Lindau disease. Human Mutation. 2007;28(2):143-9. https://doi.org/10.1002/humu.20385

8. Sgambati MT, Stolle C, Choyke PL, Walther MM, Zbar B, Linehan WM, et al. Mosaicism in von Hippel-Lindau disease: lessons from kindreds with germline mutations identified in offspring with mosaic parents. American Journal of Human Genetics. 2000;66(1):84-91.

https://doi.org/10.1086/302726

9. Maher ER, Neumann HP, Richard S. von Hippel-Lindau disease: a clinical and scientific review. European Journal of Human Genetics. 2011;19(6):617-23. https://doi.org/10.1038/ejhg.2010.175

10.Maher E, Yates J, Harries R, Benjamin C, Harris R, Moore A, et al. Clinical features and natural history of von Hippel-Lindau disease. Quarterly Journal of Medicine. 1990;77(2):1151-63. https://doi.org/10.1093/qjmed/77.2.1151

11.Walther MM, Choyke PL, Glenn G, Lyne JC, Rayford W, Venzon $\mathrm{D}$, et al. Renal cancer in families with hereditary renal cancer: prospective analysis of a tumor size threshold for renal parenchymal sparing surgery. The Journal of Urology. 1999;161(5):1475-9.

https://doi.org/10.1016/S0022-5347(05)68930-6

12. Choyke PL, Glenn GM, Walther MM, Patronas NJ, Linehan WM, Zbar B. von Hippel-Lindau disease: genetic, clinical, and imaging features. Radiology. 1995;194(3):629-42.

https://doi.org/10.1148/radiology.194.3.7862955

13.Peng X, Chen J, Wang J, Peng S, Liu S, Ma K, et al. Natural history of renal tumours in von Hippel-Lindau disease: a large retrospective study of Chinese patients. Journal of Medical Genetics. 2019;56(6):380-7.

https://doi.org/10.1136/jmedgenet-2018-105567

14.Steinbach F, Novick AC, Zincke H, Miller DP, Williams RD, Lund G, et al. Treatment of renal cell carcinoma in von HippelLindau disease: a multicenter study. The Journal of Urology. 1995;153(6):1812-6.

https://pubmed.ncbi.nlm.nih.gov/7752324/

https://doi.org/10.1016/S0022-5347(01)67318-X

15.Choyke PL, Pavlovich CP, Daryanani KD, Hewitt SM, Linehan WM, Walther MM. Intraoperative ultrasound during renal parenchymal sparing surgery for hereditary renal cancers: a 10year experience. The Journal of Urology. 2001;165(2):397-400. https://doi.org/10.1097/00005392-200102000-00010

16.Ebbing J, Menzel F, Frumento P, Miller K, Ralla B, Fuller TF, et al. Outcome of kidney function after ischaemic and zeroischaemic laparoscopic and open nephron-sparing surgery for renal cell cancer. BMC Nephrology. 2019;20(1):1-17.

https://doi.org/10.1186/s12882-019-1215-3

17.Jayarajah U, Balagobi B, Gunasekara D, Abeygunasekera AM. Management of renal malignancies in Von Hippel Lindau (VHL) syndrome: Lessons learnt from a series of six patients from Sri Lanka. Saudi Journal of Kidney Diseases and Transplantation. 2021;32: In press.

18.Roupret M, Hopirtean V, Mejean A, Thiounn N, Dufour B, Chretien $Y$, et al. Nephron sparing surgery for renal cell carcinoma and von Hippel-Lindau's disease: a single center experience. The Journal of Urology. 2003;170(5):1752-5. https://doi.org/10.1097/01.ju.0000092780.85876.de

19. Chauveau D, Duvic C, Chrétien Y, Paraf F, Droz D, Melki P, et al. Renal involvement in von Hippel-Lindau disease. Kidney International. 1996;50(3):944-51.

https://doi.org/10.1038/ki.1996.395

20.Goldfarb DA, Neumann HP, Penn I, Novick AC. Results of renal transplantation in patients with renal cell carcinoma and von Hippel-Lindau disease. Transplantation. 1997;64(12):1726-9. https://doi.org/10.1097/00007890-199712270-00017

21.Young EE, Castle SM, Gorbatiy V, Leveillee RJ. Comparison of safety, renal function outcomes and efficacy of laparoscopic and percutaneous radio frequency ablation of renal masses. The Journal of Urology. 2012;187(4):1177-82.

https://doi.org/10.1016/j.juro.2011.11.099

22.Pickersgill NA, Vetter JM, Kim EH, Cope SJ, Du K, Venkatesh R, et al. Ten-Year Experience with Percutaneous Cryoablation of Renal Tumors: Tumor Size Predicts Disease Progression. Journal of Endourology. 2020;34(12):1211-7.

https://doi.org/10.1089/end.2019.0882

23.Yang B, Autorino R, Remer EM, Laydner HK, Hillyer S, Altunrende F, et al. Probe ablation as salvage therapy for renal tumors in von Hippel-Lindau patients: the Cleveland Clinic experience with 3 years follow-up. Urologic Oncology. 2013;31(5):686-92.

https://doi.org/10.1016/j.urolonc.2011.05.008

24.Park BK, Kim CK, Park SY, Shen SH. Percutaneous radiofrequency ablation of renal cell carcinomas in patients with von Hippel Lindau disease: indications, techniques, complications, and outcomes. Acta Radiologica. 2013;54(4):418-27.

https://doi.org/10.1177/0284185113475441

25. Walther MM, Choyke PL, Glenn G, Lyne JC, Rayford W, Venzon $\mathrm{D}$, et al. Renal cancer in families with hereditary renal cancer: prospective analysis of a tumor size threshold for renal parenchymal sparing surgery. The Journal of Urology. 1999;161(5):1475-9.

https://doi.org/10.1016/S0022-5347(05)68930-6

26.Jayarajah U, Varothayan S, Jayasinghe R, Seneviratne S. Present status of cancer burden in Sri Lanka based on GLOBOCAN estimates. South Asian Journal of Cancer. 2021;10: In Press.

27.Ambegoda M, Paranamanna R, Kumara S, Balagobi B, Sosai C, Pathmeswaran A, et al. Clinicopathological characteristics and oncological outcomes of patients with renal cell carcinoma. Ceylon Medical Journal. 2020;65(3):62-6. https://doi.org/10.4038/cmj.v65i3.9187

28.Fernando H, Jayarajah U, Herath K, Goonewardena S. Clinicopathological study of adult renal tumours in a Tertiary Care Urology Unit in Sri Lanka: a retrospective analysis. International Journal of Urology. 2019;26(S2):190https://doi.org/10.1111/iju.14063

29.Jayarajah U, Abeygunasekera AM. Cancer services in Sri Lanka: current status and future directions. Journal of the Egyptian National Cancer Institute. 2021;33(1):1-7. https://doi.org/10.1186/s43046-021-00070-8 